\title{
ELSEVIER_APT_1739
}

Original Research Paper

\section{Influence of the reduction strategy in the synthesis of reduced graphene oxide}

\section{M.P. Lavin-Lopez ${ }^{\mathrm{a} *}$}

pradolavin@graphenano.com

A. Paton-Carrero ${ }^{\circ}$

L. Sanchez-Silva

J.L. Valverde

A. Romerob

aGraphenano S.L., Calle Pablo Casals 13, 30510 Yecla, Murcia, Spain

bUniversity of Castilla-La Mancha, Department of Chemical Engineering, Avenida Camilo Jose Cela 12, 13071 Ciudad Real, Spain ${ }^{*}$ Corresponding author.

\section{Abstract}

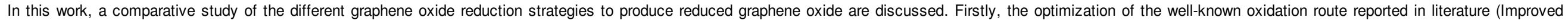

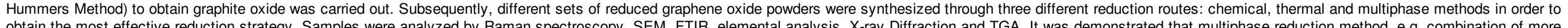

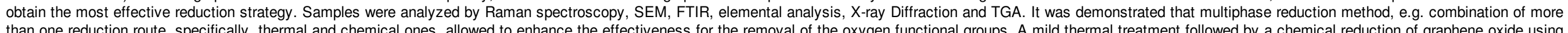

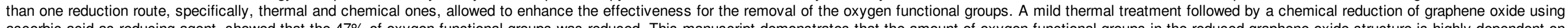

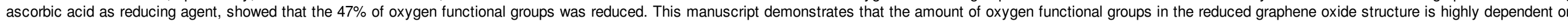
the reduction strategy. These amount of oxygen functional groups could directly affect the use of reduced graphene oxide in the different potential applications proposed in bibliography.

Keywords: Reduced graphene oxide; Removal of oxygen functional groups; Chemical reduction; Thermal reduction; Multiphase reduction

\section{Introduction}

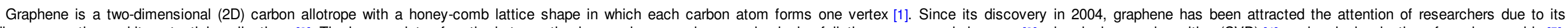

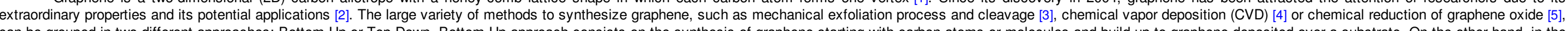

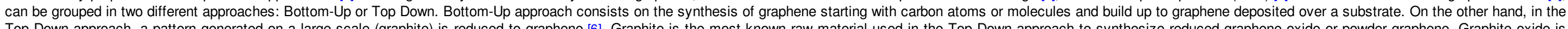

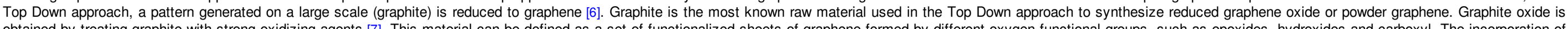

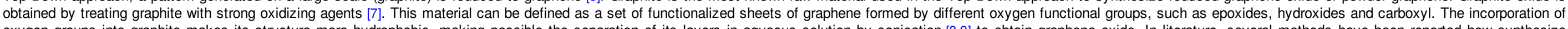

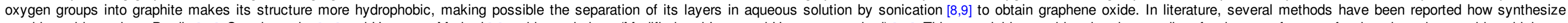

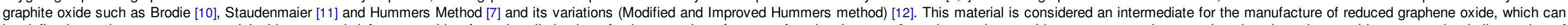

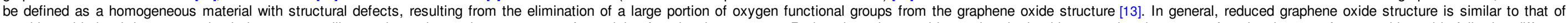

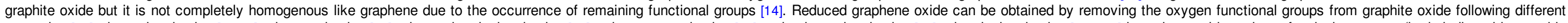

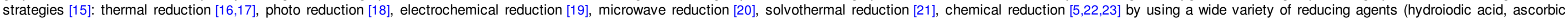
acid, hydrazine, $\mathrm{NaBH}_{4}$ or some metal hydrides [15]) and multiphase reduction [24-26]. Fig. 1 summarizes the advantages and disadvantages of the most important reduction techniques listed above. 


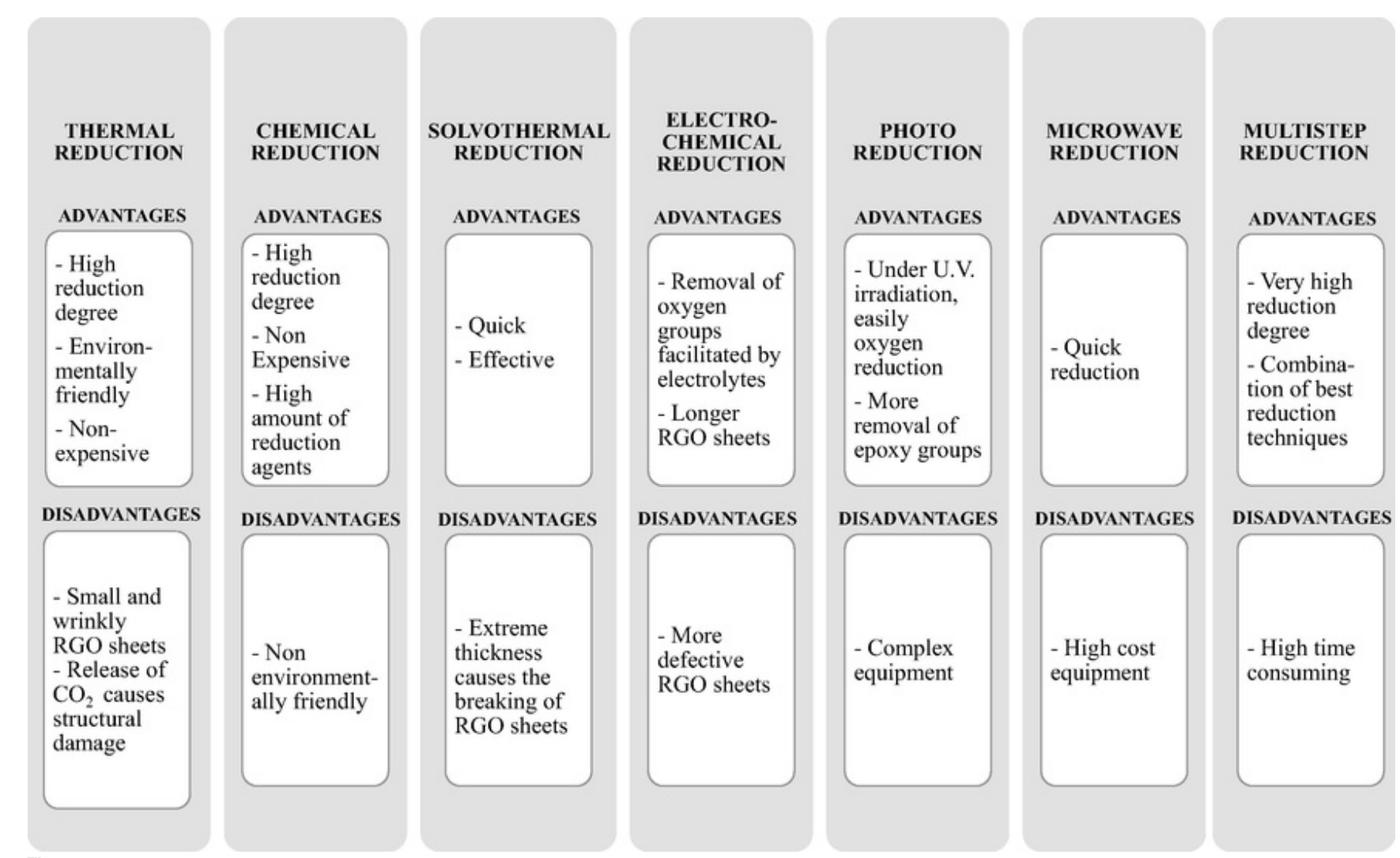

Fig. 1 Advantages and disadvantages of reduction strategies used in the production of reduced graphene oxide.

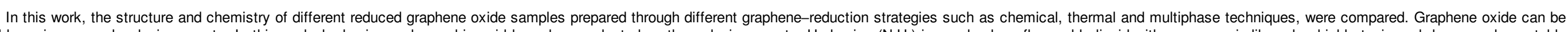

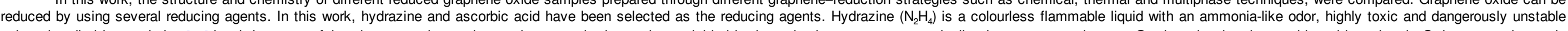

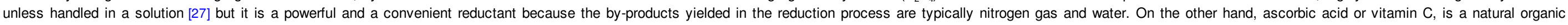

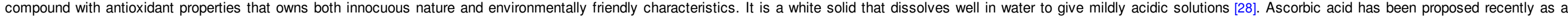

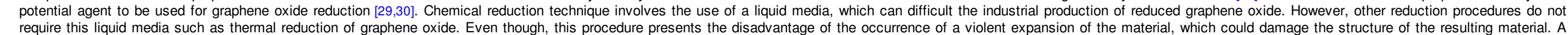
combination of both chemical and thermal reduction techniques was performed. The resulting products were compared to those separately obtained with each of the above-mentioned techniques.

\section{Materials and methods}

\subsection{Materials}

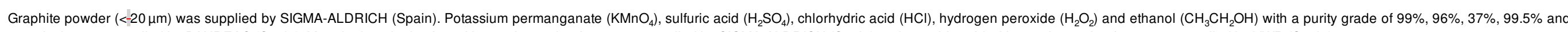
$99.5 \%$, respectively, were supplied by PANREAC (Spain). Monohydrate hydrazine with a purity grade of $98 \%$ was supplied by SIGMA-ALDRICH (Spain) and ascorbic acid with a purity grade of $99 \%$ was supplied by VWR (Spain).

\subsection{Methods}

\subsubsection{Synthesis of graphite oxide (GrO)}

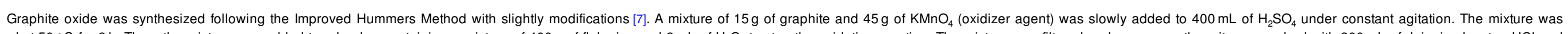

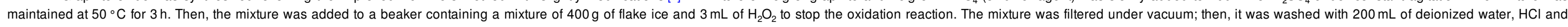
$\mathrm{CH}_{3} \mathrm{CH}_{2} \mathrm{OH}$. Finally, the compact cake was dried at $100{ }^{\circ} \mathrm{C}$ overnight. 


\section{ELSEVIER_APT_1739}

\subsubsection{Synthesis of graphene oxide (GO)}

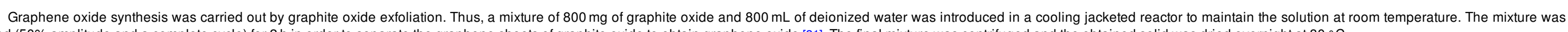
sonicated ( $50 \%$ amplitude and a complete cycle) for $2 \mathrm{~h}$ in order to separate the graphene sheets of graphite oxide to obtain graphene oxide [31]. The final mixture was centrifuged and the obtained solid was dried overnight at $80{ }^{\circ} \mathrm{C}$.

\subsubsection{Synthesis of reduced graphene oxide: reduction strategies}

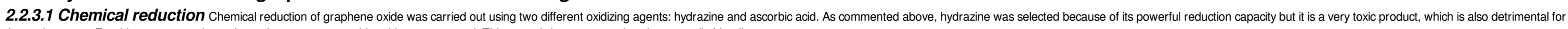
the environment. For this reason, an alternative reducer agent, ascorbic acid, was proposed. This agent is innocuous and environmentally friendly.

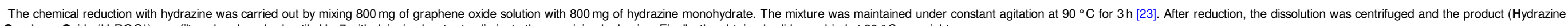
Reduced Graphene Oxide ( $\mathrm{H}$-RGO)) was fitered and washed until pH $=7$ with deionized water to eliminate the remaining hydrazine. Finally, the obtained solid was dried at $80^{\circ} \mathrm{C}$ overnight.

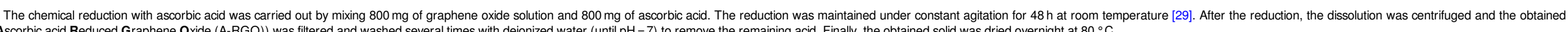
product (Ascorbic acid Reduced Graphene Oxide (A-RGO)) was fittered and washed several times with deionized water (until pH $=7$ ) to remove the remaining acid. Finally, the obtained solid was dried overnight at $80^{\circ} \mathrm{C}$.

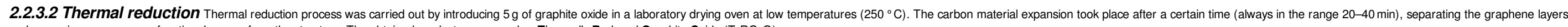
and, removing some oxygen functional groups from the structure. The obtained product was named as Thermally Reduced Graphite Oxide (T-RGrO).

After thermal reduction, $800 \mathrm{mg}$ T-RGrO was sonicated ( $30 \%$ amplitude) for $2 \mathrm{~h}$ in $800 \mathrm{~mL}$ of deionized water to complete its exfoliation obtaining Thermally Reduced Graphene Oxide (T-RGO).

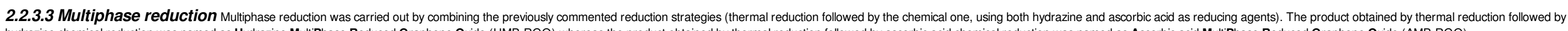

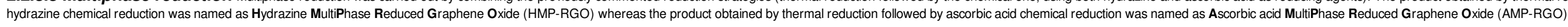

\subsection{Characterization techniques}

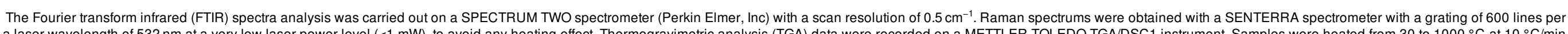

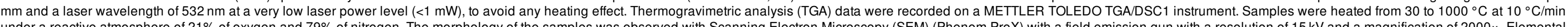

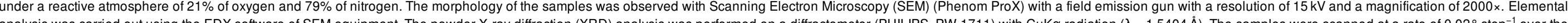

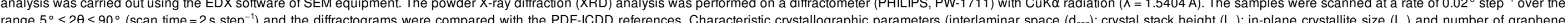

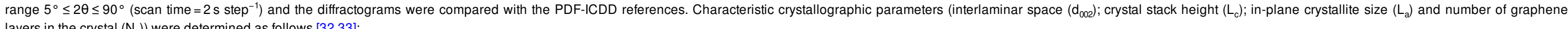
layers in the crystal $\left(\mathrm{N}_{\mathrm{c}}\right)$ ) were determined as follows [32,33]:

$\mathrm{d}_{002}=\frac{\lambda}{2 \cdot \operatorname{sen} \theta_{1}} ; \quad \mathrm{L}_{\mathrm{c}}=\frac{\mathrm{k}_{1} \cdot \lambda}{\mathrm{FWHM} \cdot \cos \theta_{1}} ;$

$\mathrm{La}(\mathrm{nm})=\frac{\mathrm{k}_{2} \cdot \lambda}{\mathrm{FWHM} \cdot \cos \theta_{2}} ; \quad \mathrm{N}_{\mathrm{c}}=\frac{\mathrm{L}_{\mathrm{c}}}{\mathrm{d}_{002}}$

where:

$-\lambda$, radiation wavelength $(\lambda=0.15404 \mathrm{~nm})$

$-\theta_{1},\left[\begin{array}{lll}0 & 0 & 2\end{array}\right]$ and $[001]$ diffraction peak position $\left({ }^{\circ}\right)$

- $\theta_{2},\left[\begin{array}{ll}1 & 0\end{array}\right]$ diffraction peak position $\left({ }^{\circ}\right)$

- $k_{1}$, form factor $(k=0.9)$

- $k_{2}$, Warren Form Factor constant $(k=1.84)$

- FWHM, width at half height of the corresponding diffraction peak (rad)

\section{Results and discussion}

Different reduction methods (e.g. chemical, thermal and multiphase techniques) have been used to maximize the removing of oxygen functional groups in graphite oxide.

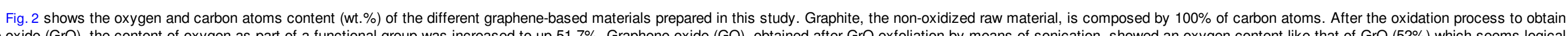

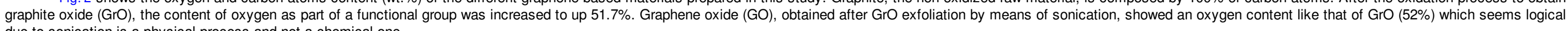
due to sonication is a physical process and not a chemical one. 


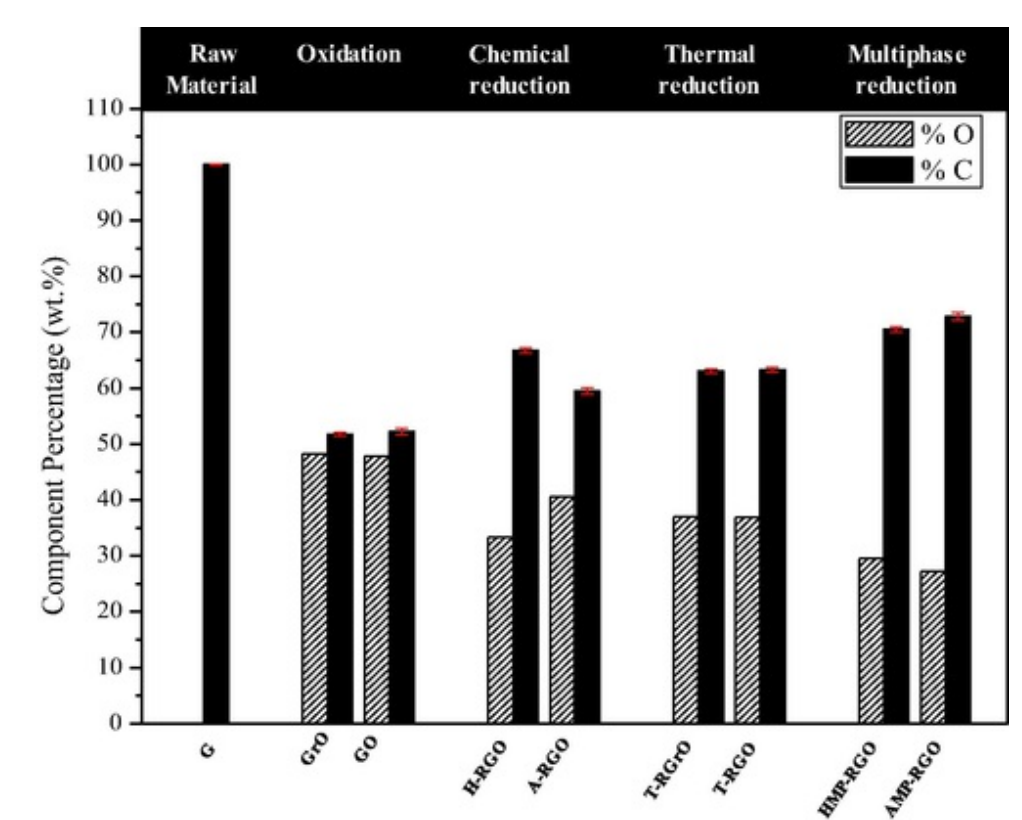

Material

Fig. 2 Elemental analysis ( $\mathrm{C}$ and $\mathrm{O}$ content) of graphite (G), graphite oxide (GrO), graphene oxide (GO) and reduced graphene oxide samples.

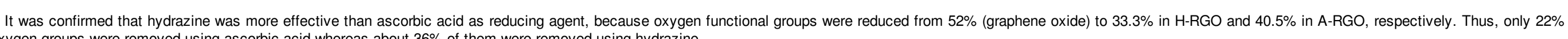
of the oxygen groups were removed using ascorbic acid whereas about $36 \%$ of them were removed using hydrazine.

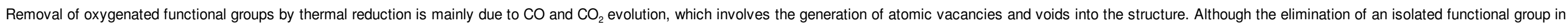

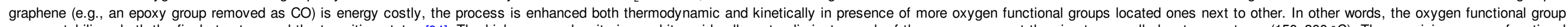

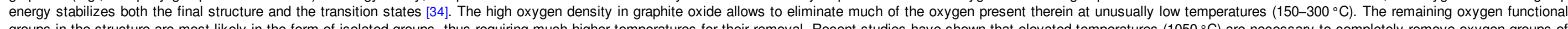

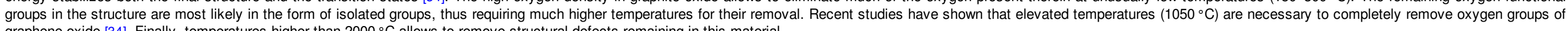
graphene oxide [34]. Finally, temperatures higher than $2000^{\circ} \mathrm{C}$ allows to remove structural defects remaining in this material.

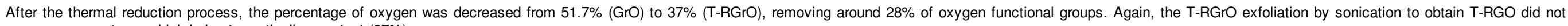
affect the oxygen percentage, which is kept practically constant $(37 \%)$.

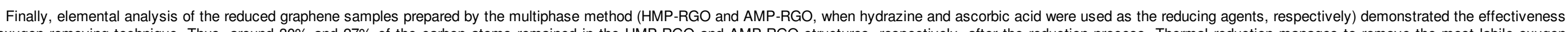

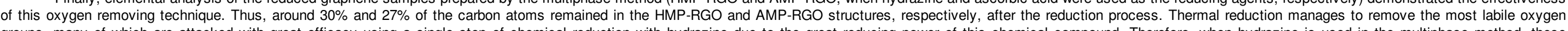

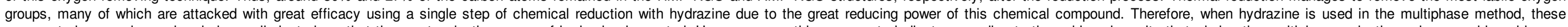

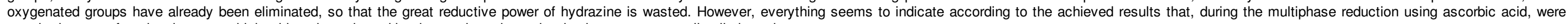
attacked oxygen functional groups which, although weakened by the previous thermal reduction, were not totally eliminated.

Consequently, AMP-RGO is the material in which higher degree of reduction was attained.

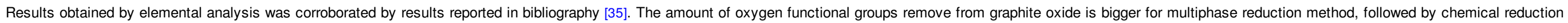
with hydrazine, thermal reduction and finally, RGO reduced using ascorbic acid as reducing agent is the one which presented more oxygen functional groups in its structure.

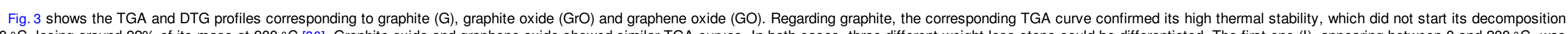

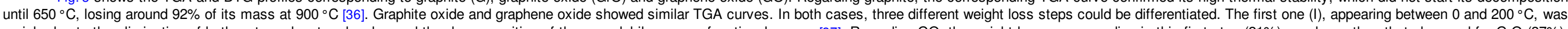

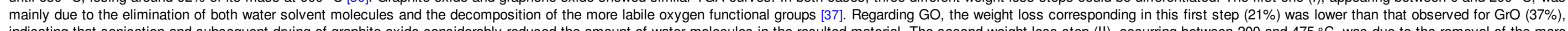

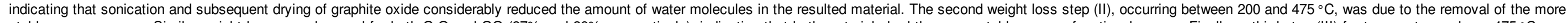

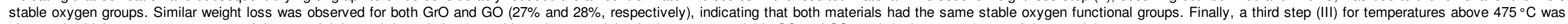
observed, which was a consequence of the material thermal degradation (unstable carbon remaining in the structure yields $\mathrm{CO}$ and $\mathrm{CO}_{2}[38]$ ), losing around $30 \%$ of the remaining mass. 


\section{ELSEVIER_APT_1739}

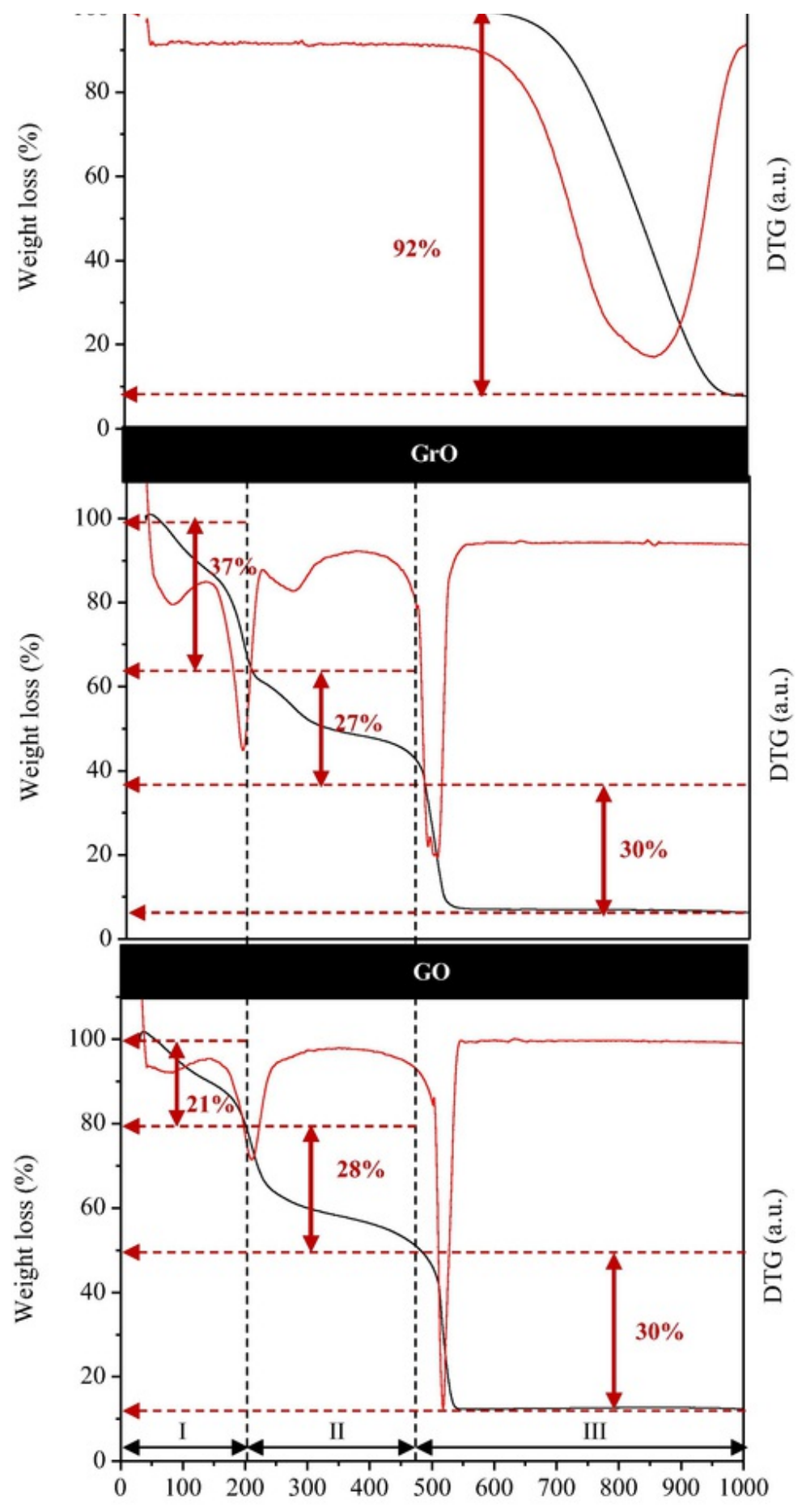




\section{ELSEVIER_APT_1739}

\section{I emperature $\left({ }^{\circ} \mathrm{C}\right)$}

Fig. 3 TGA and DTG curves of graphite (G), graphite oxide (GrO) and graphene oxide (GO).

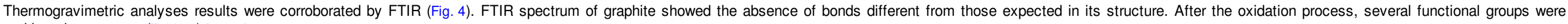
incorporated into the structure (Table 1) [38,39].

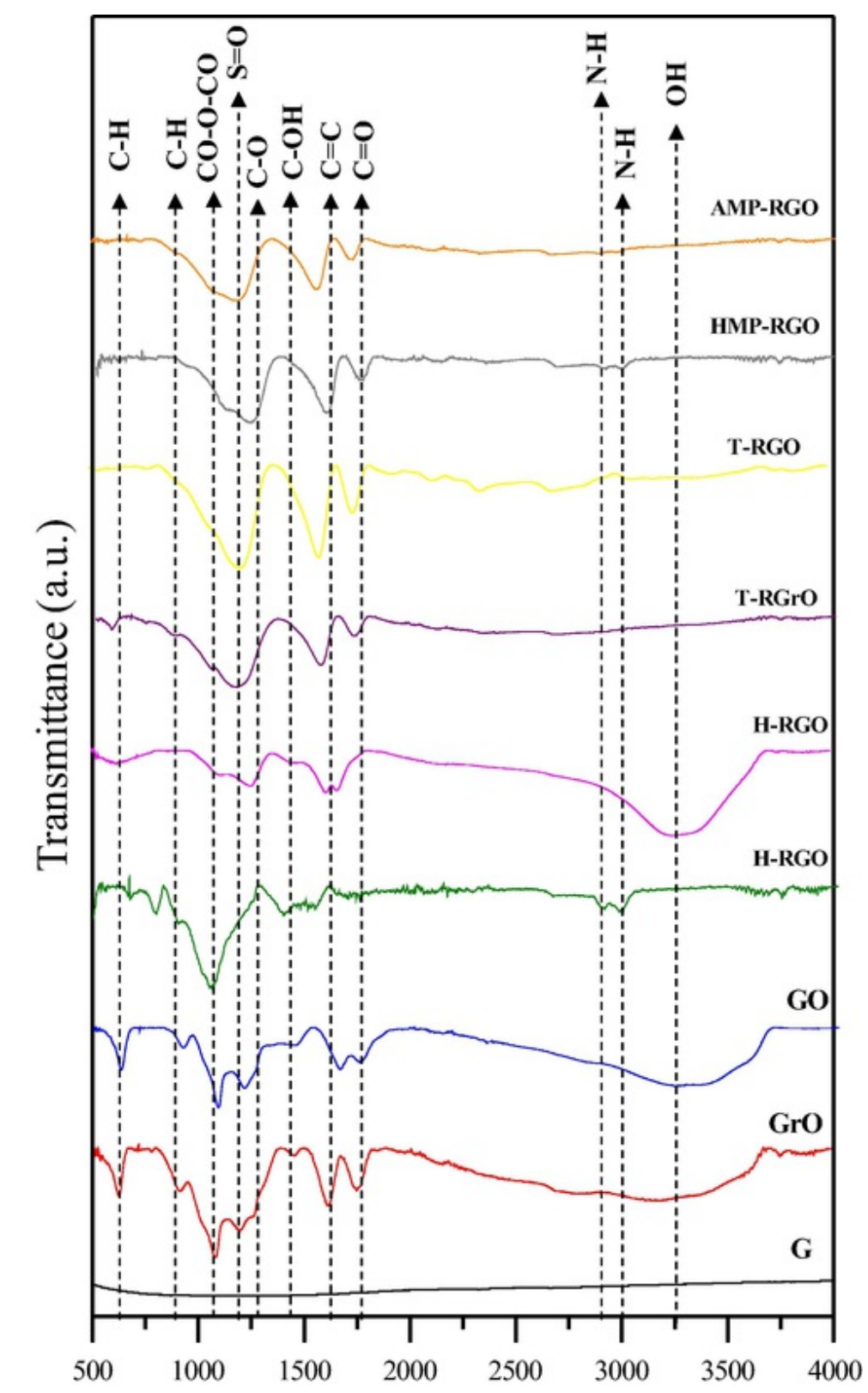

Wavelength $\left(\mathrm{cm}^{-1}\right)$ 


\section{ELSEVIER_APT_1739}

Fig. 4 FTIR analyses of graphite (G), graphite oxide (GrO), graphene oxide (GO) and reduced graphene oxide samples.

Table 1 Functional groups present in graphite (G), graphite oxide (GrO), graphene oxide (GO) and reduced graphene oxide samples [40].

Functional groups

$\mathrm{C}-\mathrm{H}$ ( $\mathrm{CH}$ group)

$\mathrm{CO}-\mathrm{O}-\mathrm{CO}$ (Anhydride group)

$\mathrm{C}$-O (Ether group)

$\mathrm{C}=\mathrm{C}$ (Alkene group)

$\mathrm{C}=\mathrm{O}$ (Ester, aldehyde and carboxylic acid groups)

$\mathrm{N}-\mathrm{H}$ (Amine group)

$\mathrm{C}-\mathrm{OH}$ (Hydroxyl group)
Wavelength $\left(\mathrm{cm}^{-1}\right)$

$755-900$

1050

1275

1650

$1720-1780$

2800-3000

1420,3700

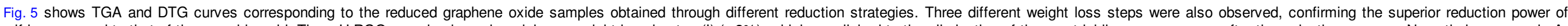

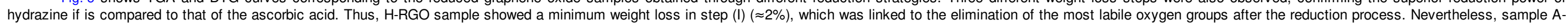

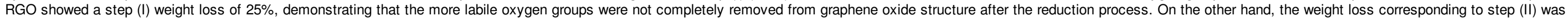

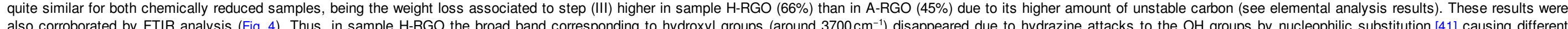

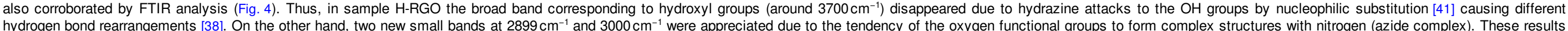
are in good agreement with those reported by Chua et al. [42], who has demonstrated through a computational study that hydrazine reduction removed favourably OH groups present in the graphene oxide basal plane. 


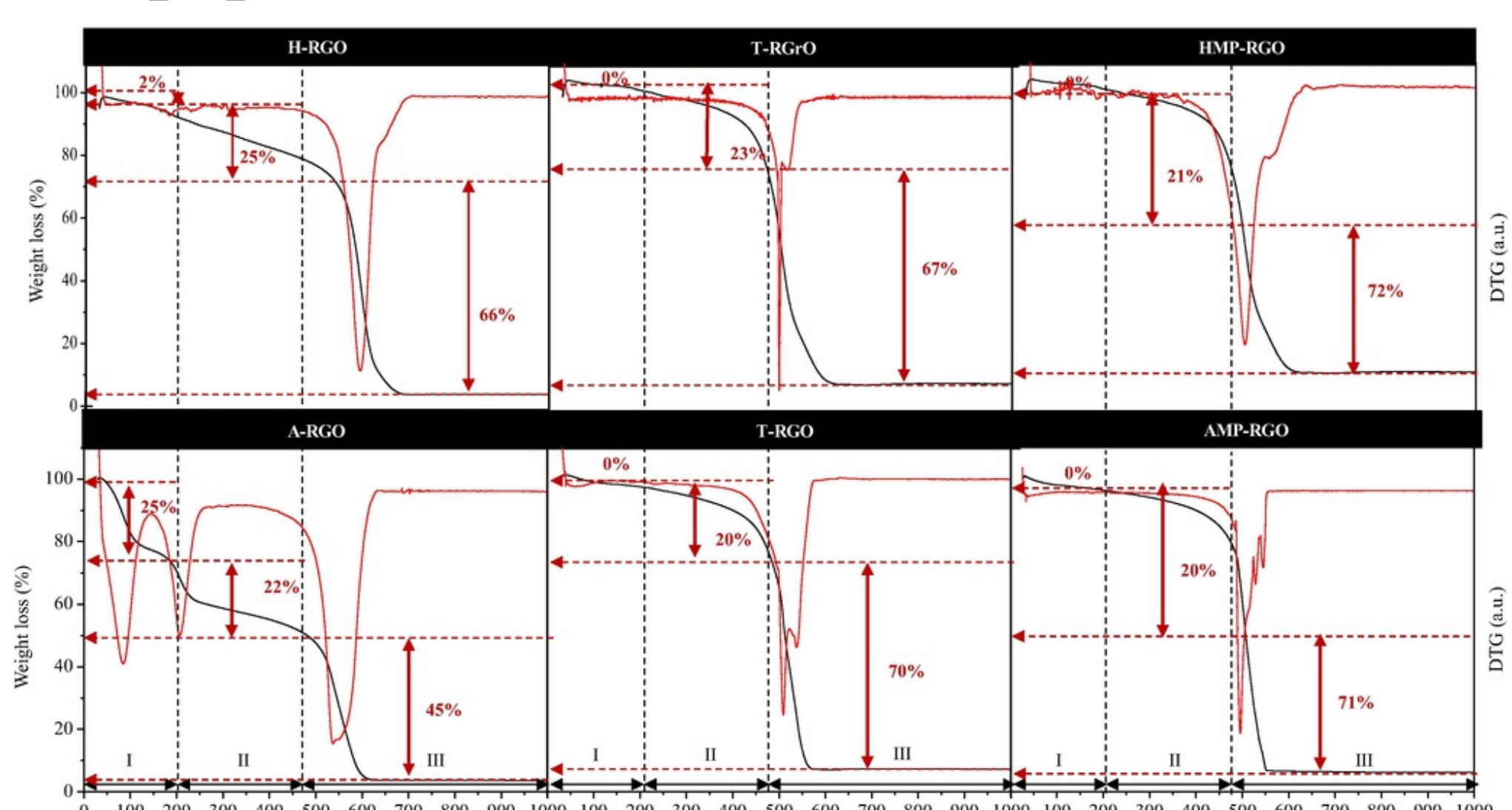

Temperature $\left({ }^{\circ} \mathrm{C}\right)$

Temperature $\left({ }^{\circ} \mathrm{C}\right)$

Temperature $\left({ }^{\circ} \mathrm{C}\right)$

Fig. 5 TGA and DTG curves of reduced graphene oxide samples.

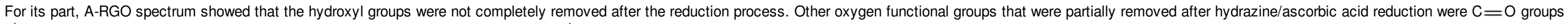

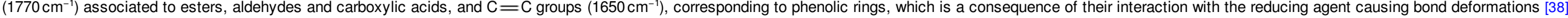

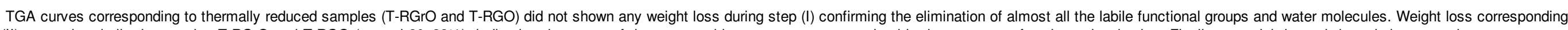

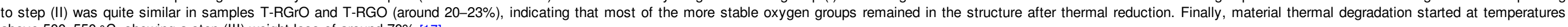
above $500-550^{\circ} \mathrm{C}$, showing a step (III) weight loss of around $70 \%[17]$

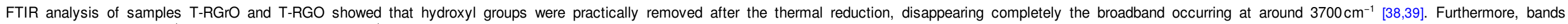
corresponding to $\mathrm{C}-\mathrm{O}\left(1275 \mathrm{~cm}^{-1}\right)$ and $\mathrm{C}=\mathrm{O}$ groups $\left(1770 \mathrm{~cm}^{-1}\right)$ were partially removed after the violent thermal expansion happened.

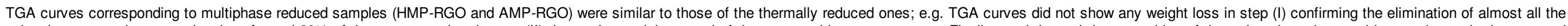

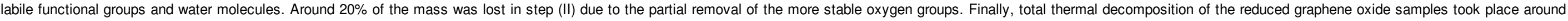

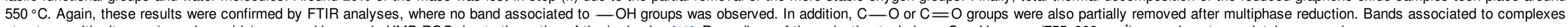
structures with nitrogen (complex azide) appeared in sample HMP-RGO due to the action of the hydrazine [42]. Regardless of the reduction technique, $\mathrm{C}-\mathrm{H}$ groups $\left(755-900 \mathrm{~cm}^{-1}\right)$ were almost completely removed.

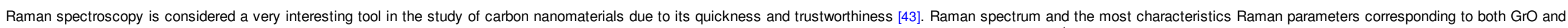

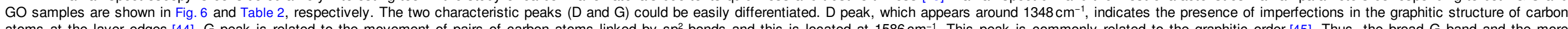

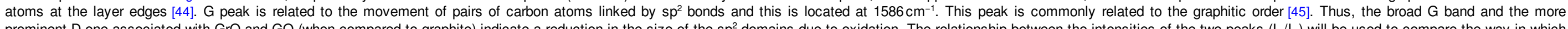

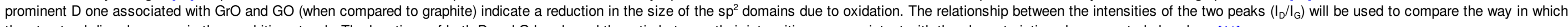
the structural disorder grows in the graphitic network. The locations of both $\mathrm{D}$ and $\mathrm{G}$ bands and the ratio between their intensities are consistent with the characteristic values reported elsewhere [41]. 


\section{ELSEVIER_APT_1739}

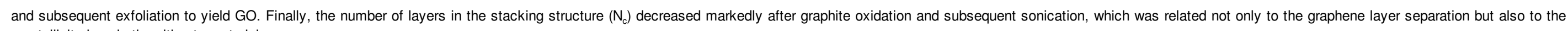
crystallinity loss in the ultimate material.

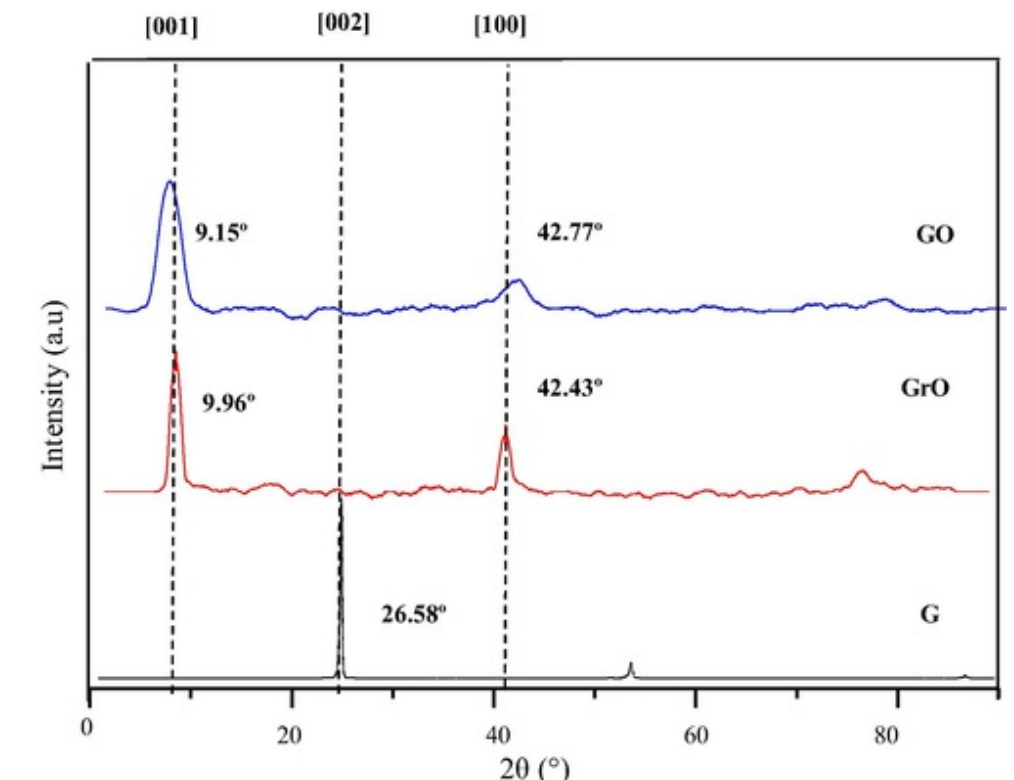

Fig. 7 XRD spectra of graphite (G), graphite oxide (GrO) and graphene oxide (GO).

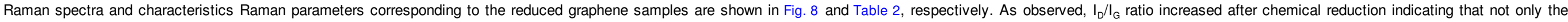

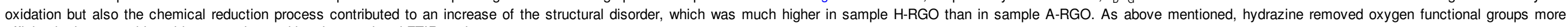
efficiently than ascorbic acid, as corroborated by elemental and FTIR analyses. 


\section{ELSEVIER_APT_1739}

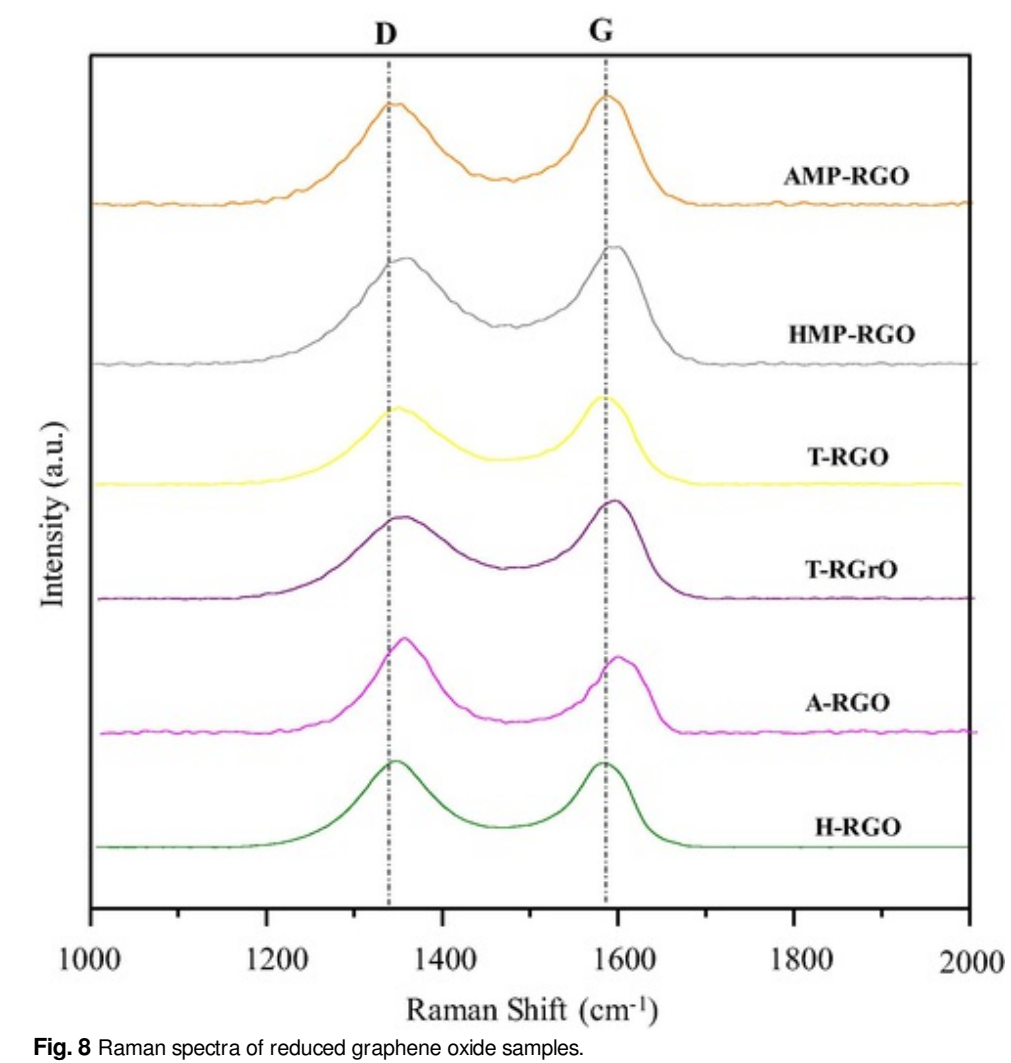

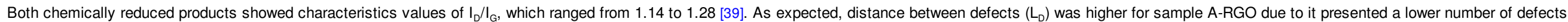

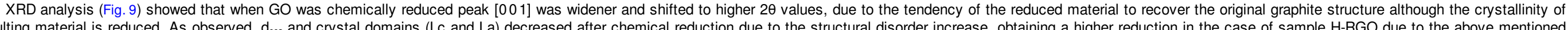

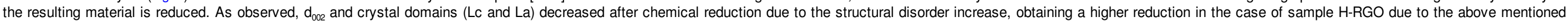
high reduction power of hydrazine. 


\section{ELSEVIER_APT_1739}

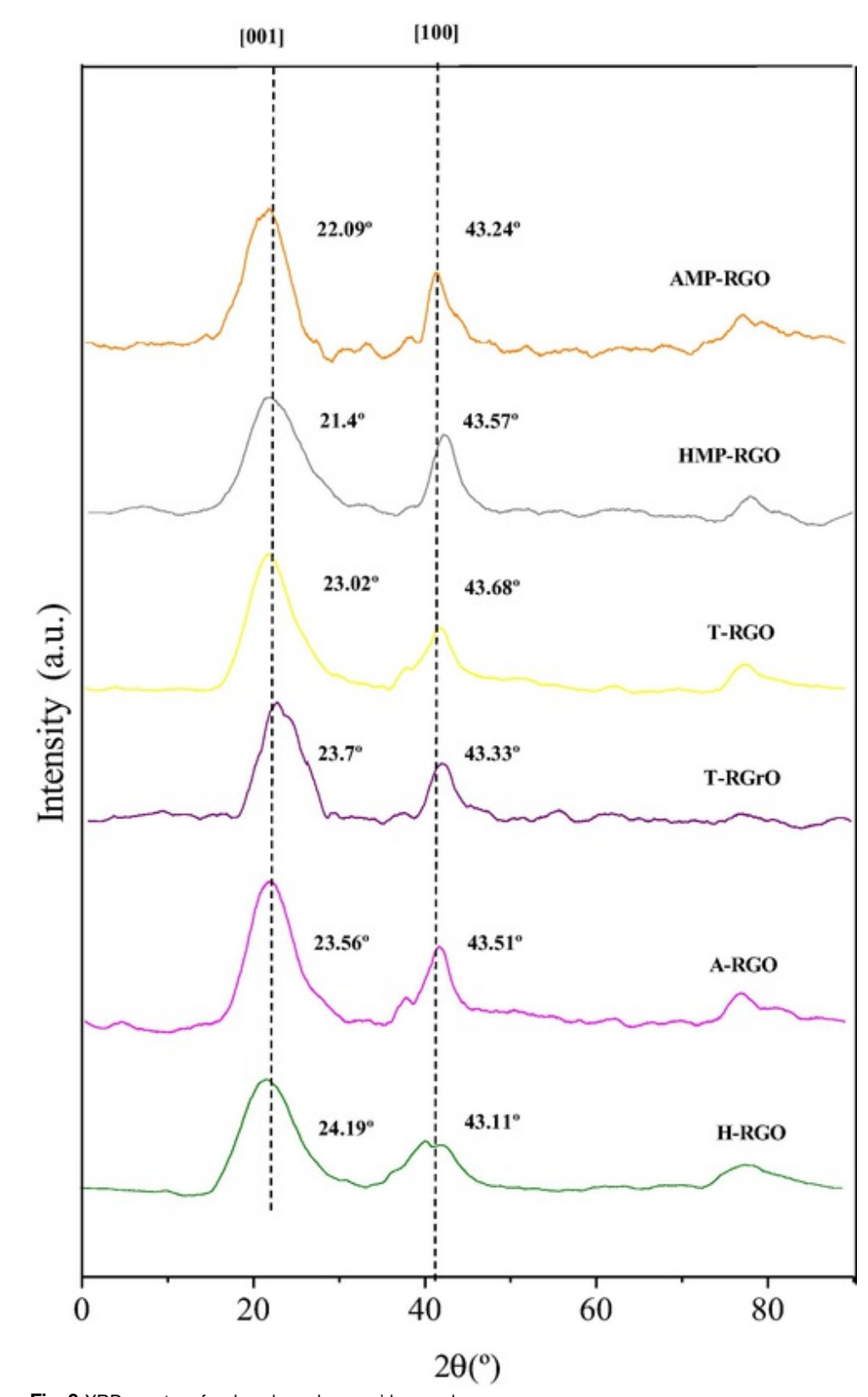

Fig. 9 XRD spectra of reduced graphene oxide samples.

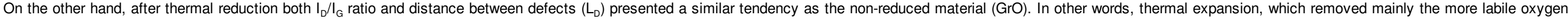

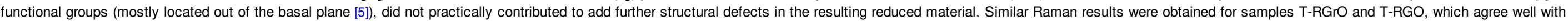
thermal and elemental analysis results.

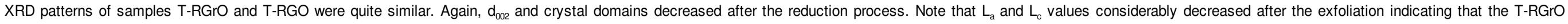
sonication to obtain T-RGO caused not only the exfoliation of the structure but also the breakage of the crystal structure. 


\section{ELSEVIER_APT_1739}

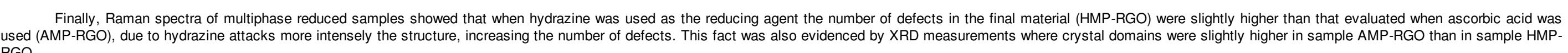
RGO.

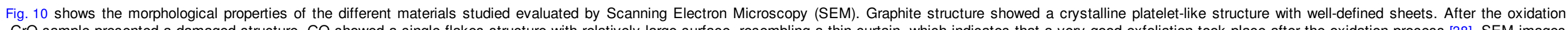

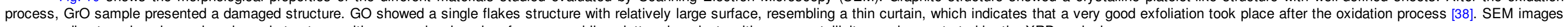
process, GrO sample presented a damaged structure. GO showed a single flakes structure with relatively large surface, resembling a thin curtain, which indicates that a very good
corresponding to reduced samples showed structures with a more developed surface, resembling cluttered products with poor crystallinity, as demonstrated by the XRD analysis. (n) 


\section{ELSEVIER_APT_1739}

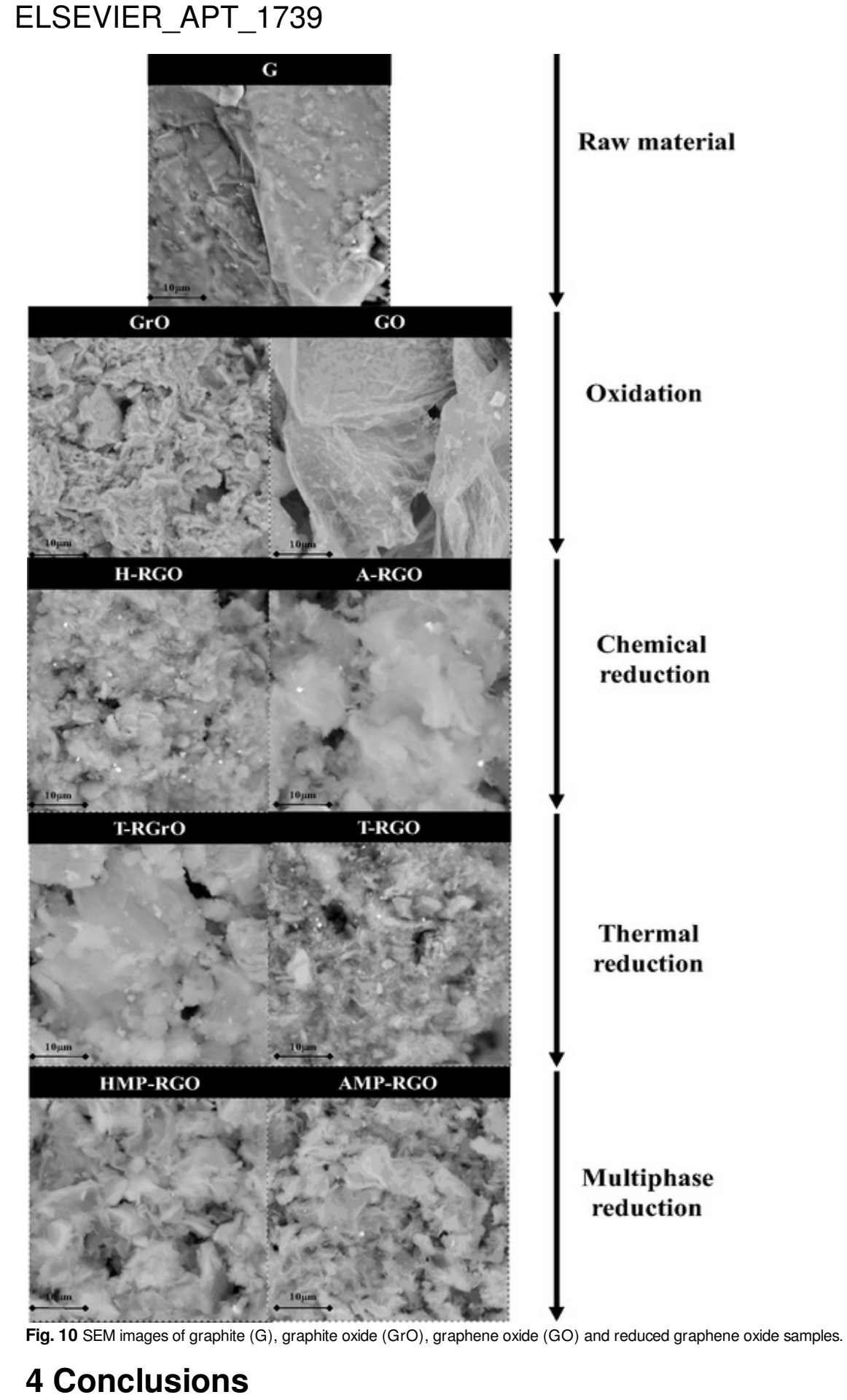

Fig. 10 SEM images of graphite (G), graphite oxide (GrO), graphene oxide (GO) and reduced graphene oxide samples. 4 Conclusions 


\section{ELSEVIER_APT_1739}

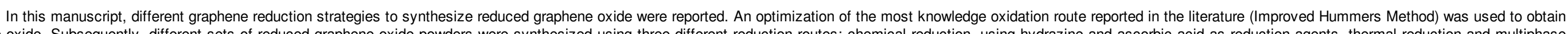

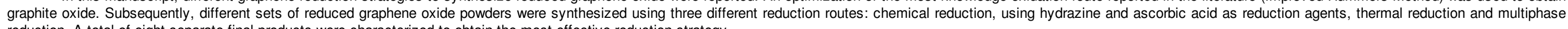
reduction. A total of eight separate final products were characterized to obtain the most effective reduction strategy.

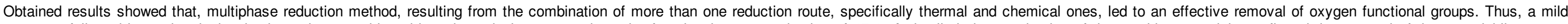

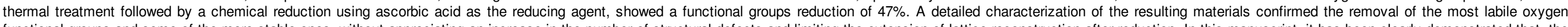

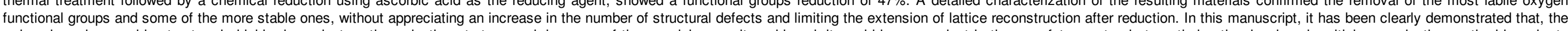

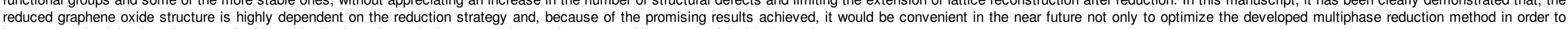
reduced graphene oxide structure is highly dependent on the reduction strategy and, because of the promising results achieved, it would bethe
increase productivity, but also to apply this method using other reducing agents that are low cost and that respectful with the environment.

\section{Acknowledgements}

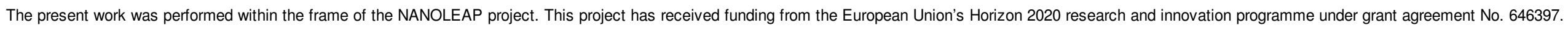

\section{References}

[1]

Q. Su, S. Pang, V. Alijani, C. Li, X. Feng and K. Müllen, Composites of graphene with large aromatic molecules, Adv. Mater. 21, 2009, 3191-3195.

[2]

Y. Zhu, S. Murali, W. Cai, X. Li, J.W. Suk, J.R. Potts and R.S. Ruoff, Graphene and graphene oxide: synthesis, properties, and applications, Adv. Mater. 22, $2010,3906-3924$.

[3]

W. Choi, I. Lahiri, R. Seelaboyina and Y.S. Kang, Synthesis of graphene and its applications: a review, Crit. Rev. Solid State Mater. Sci. 35, $2010,52-71$.

[4]

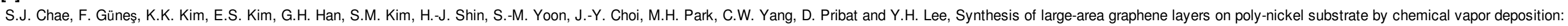
wrinkle formation, Adv. Mater. 21, 2009, 2328-2333.

[5]

C.K. Chua and M. Pumera, Chemical reduction of graphene oxide: a synthetic chemistry viewpoint, Chem. Soc. Rev. 43, 2014, 291-312.

[6]

J.M. Tour, Top-down versus bottom-up fabrication of graphene-based electronics, Chem. Mater. 26, 2014, 163-171.

[7]

W.S. Hummers, Jr and R.E. Offeman, Preparation of graphitic oxide, J. Am. Chem. Soc. 80, 1958, 1339.

[8]

S. Park and R.S. Ruoff, Chemical methods for the production of graphenes, Nat Nano 4, 2009, 217-224.

[9]

G. Shao, Y. Lu, F. Wu, C. Yang, F. Zeng and Q. Wu, Graphene oxide: the mechanisms of oxidation and exfoliation, J. Mater. Sci. 47, $2012,4400-4409$.

[10]

L.L. Abel, B.B. Levy, B.B. Brodie and F.E. Kendall, A simplified method for the estimation of total cholesterol in serum and demonstration of its specificity, J. Biol. Chem. 195, 1952 , 357-366.

[11]

L. Staudenmaier, Verfahren zur darstellung der graphitsäure, Berichte der Deutschen Chemischen Gesellschaft 31, 1898, 1481-1487.

[12]

D.C. Marcano, D.V. Kosynkin, J.M. Berlin, A. Sinitskii, Z. Sun, A. Slesarev, L.B. Alemany, W. Lu and J.M. Tour, Improved synthesis of graphene oxide, ACS Nano 4, 2010 , $4806-4814$.

[13]

K. Erickson, R. Erni, Z. Lee, N. Alem, W. Gannett and A. Zettl, Determination of the local chemical structure of graphene oxide and reduced graphene oxide, Adv. Mater. 22, $2010,4467-4472$.

[14]

A. Bagri, C. Mattevi, M. Acik, Y.J. Chabal, M. Chhowalla and V.B. Shenoy, Structural evolution during the reduction of chemically derived graphene oxide, Nat. Chem. 2, $2010,581-587$.

\section{[15]}

S. Pei and H.M. Cheng, The reduction of graphene oxide, Carbon 50, 2012, 3210-3228. 


\section{ELSEVIER_APT_1739}

[16]

S.H. Huh, Thermal Reduction of Graphene Oxide, Physics and Applications of Graphene - Experiments, in: D.S. Mikhailov (Ed.), InTech, 2011.

[17]

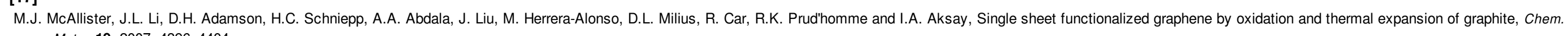
Mater. 19, 2007, 4396-4404.

[18]

Y. Zhang, L. Guo, S. Wei, Y. He, H. Xia, Q. Chen, H.B. Sun and F.S. Xiao, Direct imprinting of microcircuits on graphene oxides film by femtosecond laser reduction, Nano Today 5, 2010, 15-20.

[19]

G.K. Ramesha and N.S. Sampath, Electrochemical reduction of oriented graphene oxide films: an in situ Raman spectroelectrochemical study, J. Phys. Chem. C 113, 2009, 7985-7989.

[20]

Y. Zhu, S. Murali, M.D. Stoller, A. Velamakanni, R.D. Piner and R.S. Ruoff, Microwave assisted exfoliation and reduction of graphite oxide for ultracapacitors, Carbon 48, $2010,2118-2122$.

[21]

H. Wang, J.T. Robinson, X. Li and H. Dai, Solvothermal reduction of chemically exfoliated graphene sheets, J. Am. Chem. Soc. 131, $2009,9910-9911$.

[22]

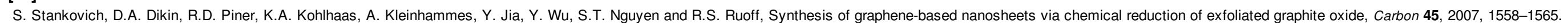

[23]

S. Park, J. An, J.R. Potts, A. Velamakanni, S. Murali and R.S. Ruoff, Hydrazine-reduction of graphite- and graphene oxide, Carbon 49, 2011, $3019-3023$.

[24]

W. Gao, L.B. Alemany, L. Ci and P.M. Ajayan, New insights into the structure and reduction of graphite oxide, Nat. Chem. 1, 2009, 403-408.

[25]

Y. Si and E.T. Samulski, Synthesis of water soluble graphene, Nano Lett. 8, 2008, 1679-1682.

[26]

C. Nethravathi and M. Rajamathi, Chemically modified graphene sheets produced by the solvothermal reduction of colloidal dispersions of graphite oxide, Carbon 46, 2008, 1994-1998.

[27]

J.-P. Schirmann, P. Bourdauducq, Hydrazine, in: Ullmann's Encyclopedia of Industrial Chemistry, Wiley-VCH Verlag GmbH \& Co. KGaA, 2000.

[28]

M.Y. Lachapelle and G. Drouin, Inactivation dates of the human and guinea pig vitamin C genes, Genetica 139, 2010, 199-207.

[29]

J. Zhang, H. Yang, G. Shen, P. Cheng and S. Guo, Reduction of graphene oxide vial-ascorbic acid, Chem. Commun. 46, 2010, 1112-1114.

[30]

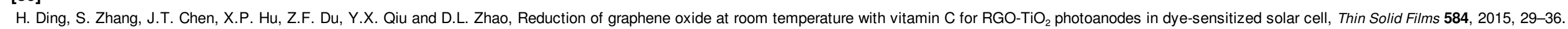

[31]

M. Choucair, P. Thordarson and J.A. Stride, Gram-scale production of graphene based on solvothermal synthesis and sonication, Nat. Nanotechnol. 4, $2009,30-33$.

[32]

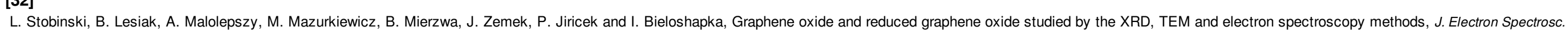
Related Phenomena 195, 2014, 145-154.

[33]

B.E. Warren, X-ray diffraction in random layer lattices, Phys. Rev. 59, 1941, 693-698.

[34]

T. Sun, S. Fabris and S. Baroni, Surface precursors and reaction mechanisms for the thermal reduction of graphene basal surfaces oxidized by atomic oxygen, J. Phys. Chem. C 115, $2011,4730-4737$. [35]

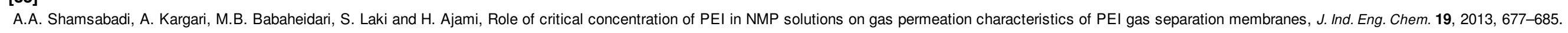




\section{ELSEVIER_APT_1739}

[36]

D.M. Crumpton, R.A. Laitinen, J. Smieja and D.A. Cleary, Thermal analysis of carbon allotropes: an experiment for advanced undergraduates, J. Chem. Educ. 73, $1996,590-591$.

[37]

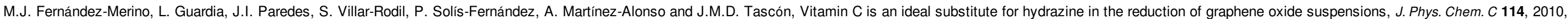
$6426-6432$.

[38]

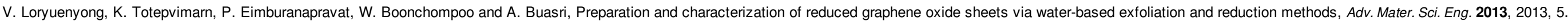
[39]

S. Eigler, C. Dotzer and A. Hirsch, Visualization of defect densities in reduced graphene oxide, Carbon 50, 2012, 3666-3673.

[40]

Chemistry, Infrared Spectroscopy Absorption Table, 2014.

[41]

J. Gao, F. Liu, Y. Liu, N. Ma, Z. Wang and X. Zhang, Environment-friendly method to produce graphene that employs vitamin C and amino acid, Chem. Mater. 22, 2010, $2213-2218$.

[42]

C.K. Chua and M. Pumera, The reduction of graphene oxide with hydrazine: elucidating its reductive capability based on a reaction-model approach, Chem. Commun. 52, $2016,72-75$.

[43]

K.N. Kudin, B. Ozbas, H.C. Schniepp, R.K. Prud'homme, I.A. Aksay and R. Car, Nano Lett. 8, 2008, 36.

[44]

P.S. Fernández, Modificación superficial de materiales de carbono: grafito y grafeno, 2011, Departamento de Ciencia de los Materiales e Ingeniería Metalúrgica. Universidad de Oviedo.

[45]

A.C. Ferrari and J. Robertson, Interpretation of Raman spectra of disordered and amorphous carbon, Phys. Rev. B-Condens. Matter Mater. Phys. 61, $2000,14095-14107$.

[46]

M.M. Lucchese, F. Stavale, E.H.M. Ferreira, C. Vilani, M.V.O. Moutinho, R.B. Capaz, C.A. Achete and A. Jorio, Quantifying ion-induced defects and Raman relaxation length in graphene, Carbon 48, 2010, 1592-1597.

Graphical abstract

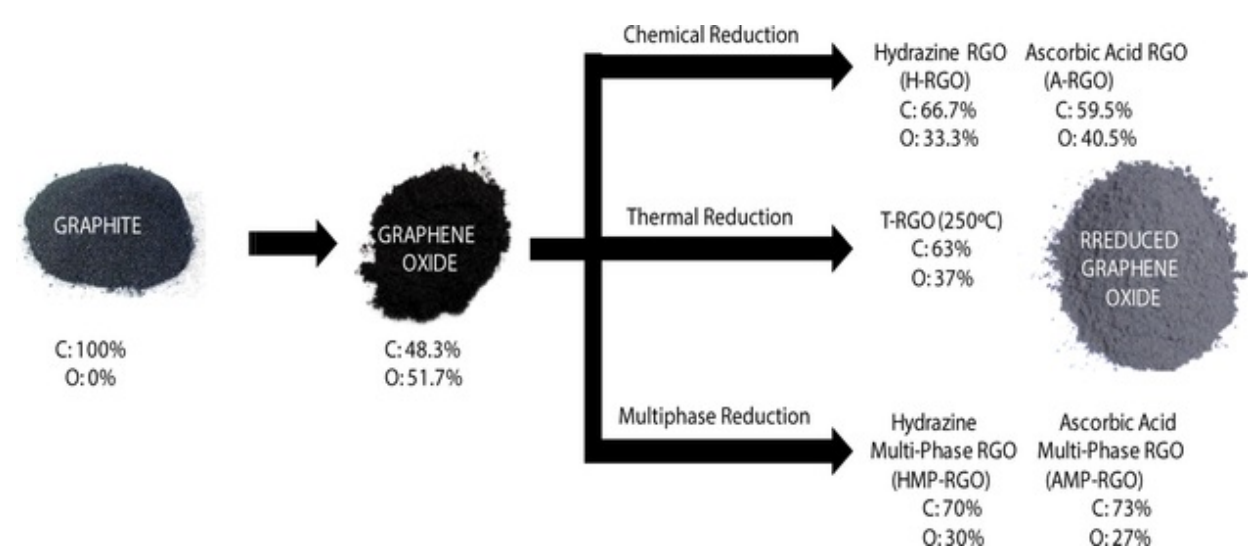

Highlights 


\section{ELSEVIER_APT_1739}

- Chemical, thermal and multiphase strategies for the synthesis of RGO are proposed.

- Lowest amount of oxygen functional groups was obtained by multiphase reduction.

- Ascorbic Acid was presented as the best reduction agent in multiphase reduction.

- Multiphase reduction does not increase the number of defects in RGO structure.

- Structure and application of RGO highly depend on the reduction strategy followed.

\section{Queries and Answers}

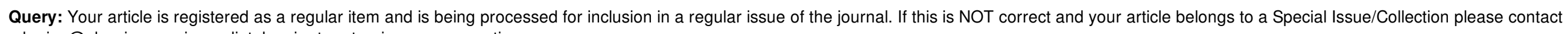
a.kurian@elsevier.com immediately prior to returning your corrections.

Answer: Yes, my article should be included in a regular issue.

Query: The author names have been tagged as given names and surnames (surnames are highlighted in teal color). Please confirm if they have been identified correctly.

Answer: Yes, the surnames have been identified correctly.

\section{Query: Please check the hierarchy of the section headings.}

Answer: Yes 